\title{
Association of pre-operative chronic kidney disease and acute kidney injury with in- hospital outcomes of emergency colorectal surgery: a cohort study
}

Katsunori Miyake ${ }^{1,2,3}$, Masao Iwagami ${ }^{4,5^{*}}$, Takayasu Ohtake ${ }^{1}$, Hidekazu Moriya ${ }^{1}$, Nao Kume ${ }^{6}$, Takaaki Murata ${ }^{6}$, Tomoki Nishida ${ }^{6}$, Yasuhiro Mochida ${ }^{1}$, Naoko Isogai ${ }^{6}$, Kunihiro Ishioka ${ }^{1}$, Rai Shimoyama ${ }^{6}$, Sumi Hidaka ${ }^{1}$, Hiroyuki Kashiwagi ${ }^{6}$, Jun Kawachi ${ }^{6}$, Hidemitsu Ogino ${ }^{7}$ and Shuzo Kobayashi ${ }^{1}$

\begin{abstract}
Background: Pre-operative kidney function is known to be associated with surgical outcomes. However, in emergency surgery, the pre-operative kidney function may reflect chronic kidney disease (CKD) or acute kidney injury (AKI). We examined the association of pre-operative CKD and/or AKI with in-hospital outcomes of emergency colorectal surgery.

Methods: We conducted a retrospective cohort study including adult patients undergoing emergency colorectal surgery in 38 Japanese hospitals between 2010 and 2017. We classified patients into five groups according to the pre-operative status of CKD (defined as baseline estimated glomerular filtration rate $<60 \mathrm{~mL} / \mathrm{min} / 1.73 \mathrm{~m}^{2}$ or recorded diagnosis of $C K D$ ), AKI (defined as admission serum creatinine value/baseline serum creatinine value $\geq$ 1.5), and end-stage renal disease (ESRD): (i) CKD(-)AKI(-), (ii) CKD(-)AKI(+), (iii) CKD(+)AKI(-), (iv) CKD(+)AKI(+), and (v) ESRD groups. The primary outcome was in-hospital mortality, while secondary outcomes included use of vasoactive drugs, mechanical ventilation, blood transfusion, post-operative renal replacement therapy, and length of hospital stay. We compared these outcomes among the five groups, followed by a multivariable logistic regression analysis for in-hospital mortality.

Results: We identified 3002 patients with emergency colorectal surgery (mean age $70.3 \pm 15.4$ years, male 54.5\%). The in-hospital mortality was 8.6\% (169/1963), 23.8\% (129/541), 15.3\% (52/340), 28.8\% (17/59), and 32.3\% (32/99) for CKD(-)AKI(-), CKD(-)AKI(+), CKD(+)AKI(-), CKD(+)AKI(+), and ESRD, respectively. Other outcomes such as blood transfusion and post-operative renal replacement therapy showed similar trends. Compared to the CKD(-)AKI(-) group, the adjusted odds ratio (95\% confidence interval) for in-hospital mortality was 2.54 (1.90-3.40), 1.29 (0.901.85), 2.86 (1.54-5.32), and 2.76 (1.55-4.93) for CKD(-)AKI(+), CKD(+)AKI(-), CKD(+)AKI(+), and ESRD groups,

(Continued on next page)
\end{abstract}

\footnotetext{
*Correspondence: iwagami-tky@umin.ac.jp

${ }^{4}$ Department of Health Services Research, University of Tsukuba, Ibaraki,

Japan

${ }^{5}$ Department of Non-Communicable Disease Epidemiology, London School of Hygiene and Tropical Medicine, London, UK

Full list of author information is available at the end of the article
}

C C The Author(s). 2020 Open Access This article is licensed under a Creative Commons Attribution 4.0 International License, which permits use, sharing, adaptation, distribution and reproduction in any medium or format, as long as you give appropriate credit to the original author(s) and the source, provide a link to the Creative Commons licence, and indicate if changes were made. The images or other third party material in this article are included in the article's Creative Commons licence, unless indicated otherwise in a credit line to the material. If material is not included in the article's Creative Commons licence and your intended use is not permitted by statutory regulation or exceeds the permitted use, you will need to obtain permission directly from the copyright holder. To view a copy of this licence, visit http://creativecommons.org/licenses/by/4.0/ The Creative Commons Public Domain Dedication waiver (http://creativecommons.org/publicdomain/zero/1.0/) applies to the data made available in this article, unless otherwise stated in a credit line to the data. 


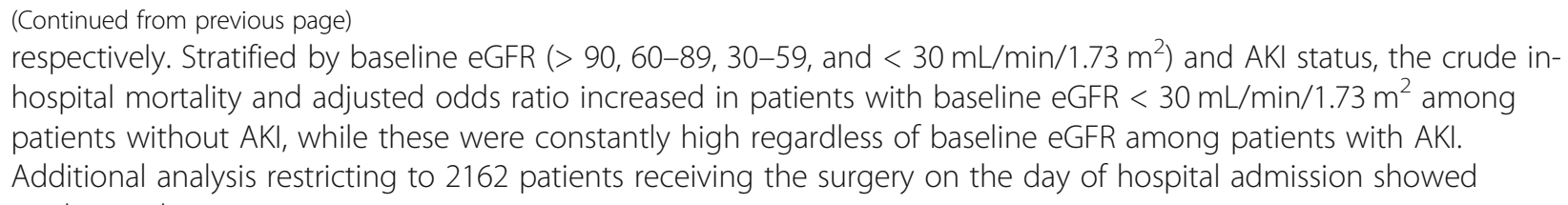

Conclusions: The differentiation of pre-operative CKD and AKI, especially the identification of AKI, is useful for risk stratification in patients undergoing emergency colorectal surgery.

Keywords: Emergency surgery, Colorectal surgery, Chronic kidney disease, Acute kidney injury, End-stage renal disease

\section{Background}

Chronic kidney disease (CKD), defined as decreased kidney function and/or the presence of kidney damage [1,2], is known to be associated with increased mortality and morbidity in both cardiac and non-cardiac surgery $[3,4]$. In the National Surgical Quality Improvement Program database, pre-operative estimated glomerular filtration rate (eGFR) was significantly associated with increased risk of mortality and complication of major abdominal surgery, including colorectal surgery [5]. However, the study focused on elective surgery, hence, excluding emergency surgery [5].

The international consensus on acute kidney injury (AKI) was also established in the twentieth century [6]. Accordingly, there has been a large amount of evidence that postoperative incidence of AKI was associated with worse prognoses of cardiac and non-cardiac surgery [7-9]. However, most of the previous studies focused on post-operative AKI, instead of pre-operative AKI, in elective surgery [7-9]. This is probably because, in theory, the possibility of preoperative AKI is none or extremely small in elective surgery.

Colorectal surgery is the most common type of major abdominal surgery [5]. If the lower gastrointestinal tract is blocked or perforated, colorectal surgery may be conducted as an emergency surgery; patients may have dehydration and sepsis pre-operatively, which are wellknown risk factors for AKI [10]. Therefore, patients undergoing emergency colorectal surgery may also have pre-operative AKI, with or without baseline CKD. However, to our knowledge, there has been no study differentiating between pre-operative CKD and AKI status in emergency surgery.

Therefore, using the electronic health records of a large hospital chain in Japan, we examined the association of pre-operative CKD and/or AKI with in-hospital outcomes in patients with emergent colorectal surgery.

\section{Methods}

\section{Data source}

We conducted a retrospective cohort study, using the Tokushukai Medical Database [11]. The Tokushukai
Group is a large Japanese hospital chain, managing over 70 hospitals across Japan, including 38 hospitals which participated in the Diagnosis Procedure Combination (DPC) system, a lump-sum payment system in Japan [12]. The Tokushukai Medical Database mainly consists of administrative claims data (namely, the DPC inpatient data) and electronic health records, including inpatient and outpatient blood test results. The DPC inpatient data include the following information: patients' age and sex; admission and discharge dates; discharge status (dead or alive); main diagnosis, comorbidities at admission, and post-admission complications recorded by the attending physician using the 2003 version of the International Classification Disease 10th revision (ICD-10) codes [13]; types of surgery (coded with original codes and text data in Japanese); and drugs and procedures, including mechanical ventilation and renal replacement therapy (RRT), on a daily basis. In a previous validation study in the Japanese DPC inpatient data, sensitivity, specificity, positive predictive value, and negative predictive value of chronic renal failure diagnosis were $53.3 \%, 99.3 \%, 80.0 \%$, and $97.7 \%$, respectively [14].

The study was approved by the Tokushukai Group Joint Ethics Committee (reference number TGE00947024) and conducted in adherence with the tenets of the Declaration of Helsinki. Informed consent from individual patients was waived because all data were anonymized for research purposes.

\section{Study population}

The study population consisted of adult patients (aged 18 years or older) who were admitted to one of 38 hospitals (Additional file 1) participating in the Japanese DPC system in the Tokushukai Medical Database during the 7-year period between July 2010 and June 2017 and received emergency colorectal surgery within 3 days of admission. The relevant surgery was identified based on Japanese surgery codes: K639 ("surgery for acute panperitonitis"), K719 ("colectomy"), K726 or K736 ("colostomy"), and K740 ("rectal resection"). Because "surgery for acute pan-peritonitis" may be conducted not only for 
colorectal perforation but also for upper gastrointestinal perforation and cholecystitis/cholangitis, we excluded patients with both surgery codes K639 ("surgery for acute pan-peritonitis") and K646-K689 suggesting upper abdominal surgery. If a patient was hospitalized and received the emergency colorectal surgery multiple times during the study period, we included only the first event into the analysis.

\section{Exposure}

The exposure of interest was pre-operative kidney function. For study purposes, we differentiated CKD, AKI, and end-stage renal disease (ESRD) using the following steps (Fig. 1). First, we identified patients with ESRD based on the admission diagnosis of ESRD (ICD-10 code N18.0 in the 2003 version of ICD-10 codes [13]) or the evidence of maintenance dialysis prior to the current admission, including hemodialysis and peritoneal dialysis. Next, we classified patients with and without CKD based on admission diagnosis of CKD (ICD-10 code N18.8 or N18.9 in the 2003 version of ICD-10 codes [13]) or baseline estimated glomerular filtration rate (eGFR) less than $60 \mathrm{ml} / \mathrm{min} / 1.73 \mathrm{~m}^{2}$, according to the Kidney Disease Improving Global Outcomes (KDIGO) CKD criteria [2]. Baseline eGFR was calculated from the baseline serum creatinine value (the most recent value recorded within 7 to 365 days prior to current hospitalization) using the Modification of Diet in Renal Disease equation for Japanese patients [15]. Finally, in each group of patients with and without CKD, we identified patients with preoperative AKI, defined as the ratio of serum creatinine value at admission and that at baseline $\geq 1.5$, according to the KDIGO AKI criteria [6]. If the baseline serum creatinine value was not available in the database, we assumed that patients without CKD diagnosis had a GFR of $75 \mathrm{~mL} / \mathrm{min} / 1.73 \mathrm{~m}^{2}$ (according to the KDIGO AKI guideline [6]), and those with CKD diagnosis had the lowest serum creatinine value noted during current hospitalization [16]. Consequently, the study participants were grouped into the following five groups: (i) CKD()AKI(-), (ii) $\mathrm{CKD}(-) \mathrm{AKI}(+)$, (iii) $\mathrm{CKD}(+) \mathrm{AKI}(-)$, (iv) $\mathrm{CKD}(+) \mathrm{AKI}(+)$, and (v) ESRD (Fig. 1).

\section{Outcomes}

The primary outcome of interest was in-hospital mortality. Secondary outcomes included use of vasoactive drugs and mechanical ventilation on the next day of surgery or later (meaning that patients could not be weaned from them on the day of surgery); requirement for blood transfusion during hospitalization, including red cell concentrate, platelet concentrate, and fresh-frozen plasma; post-operative RRT, including intermittent and continuous RRT; and length of hospital stay among hospital survivors.

\section{Covariates}

We considered the following baseline characteristics to examine the association between pre-operative CKD, AKI, or ESRD and the primary outcome (i.e., in-hospital mortality): age and sex; type of surgery based on the Japanese surgery codes (i.e., surgery for acute panperitonitis, colectomy, colostomy, or rectal resection); use of laparoscopy during operation; indication for surgery, including (i) peritonitis or perforation, (ii) obstruction, and (iii) bleeding or diverticulosis based on a list of ICD-10 codes shown in Additional file 2; presence or absence of colorectal cancer; body mass index (BMI); comorbidities, including diabetes, heart failure, chronic liver disease, chronic obstructive pulmonary disease, and cancer (except for colorectal cancer); and blood test

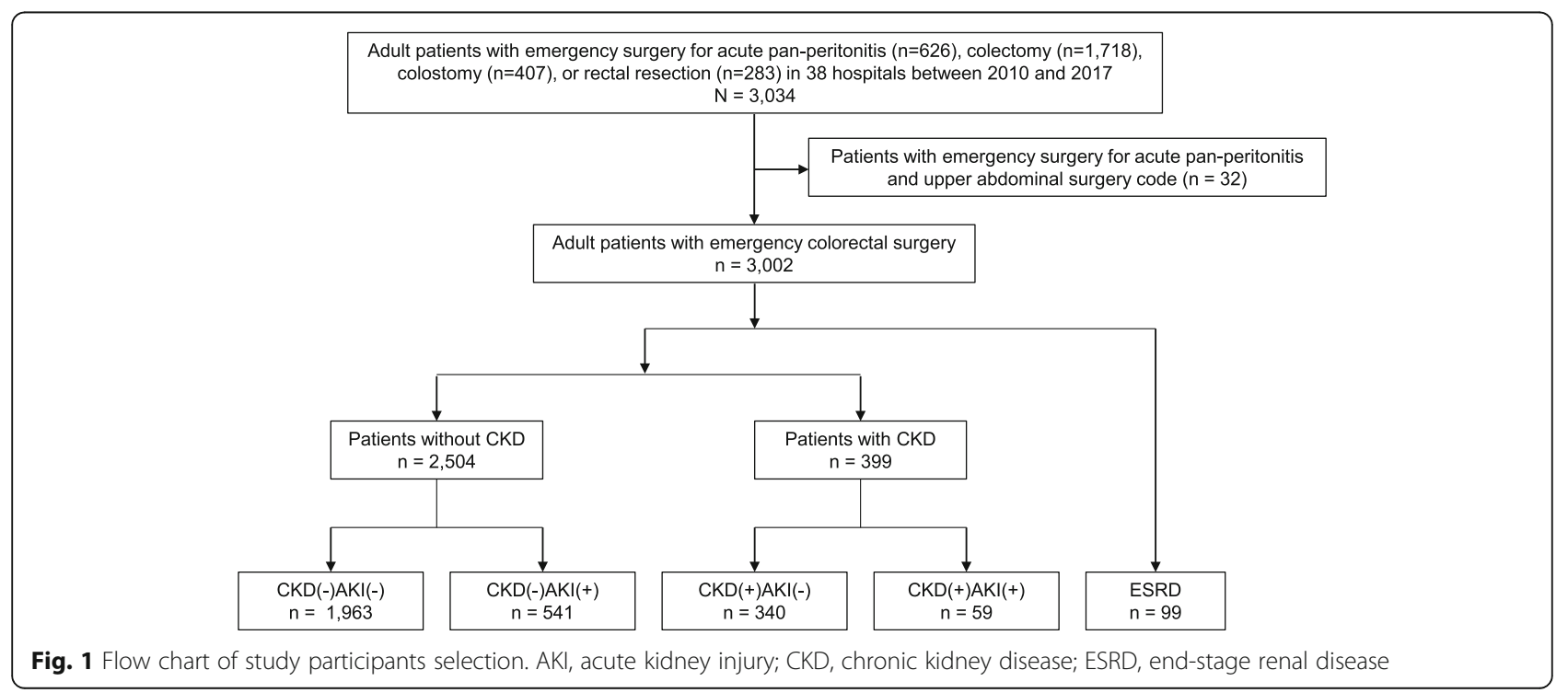


results at admission, including white blood cell count, hemoglobin, platelet count, total protein, total bilirubin, and C-reactive protein. If a patient received multiple ICD-10 codes suggestive of an indication for surgery, (i) peritonitis or perforation was assigned the highest priority, followed by (ii) obstruction, and (iii) bleeding or diverticulosis, so that each patient was classified into only one of the three categories. A small number of patients with no ICD-10 code in the code list were categorized as "others".

\section{Statistical analysis}

First, we described the baseline patient characteristics by the five groups: (i) CKD(-)AKI(-), (ii) CKD(-)AKI(+), (iii) $\mathrm{CKD}(+) \mathrm{AKI}(-)$, (iv) $\mathrm{CKD}(+) \mathrm{AKI}(+)$, and (v) ESRD groups. Continuous variables (such as age and BMI) were presented as mean \pm standard deviation (SD) and compared among the five groups by analysis of variance. If the distribution of the variable was skewed, we presented it as median (interquartile range [IQR]) and compared it among the five groups by Kruskal-Wallis test. Binary or categorical variables (such as sex and comorbidities) were presented as percentage and compared by chi-square tests.

Then, the study outcomes were presented and compared among the five groups, in the same way as the baseline characteristics. At subgroup analysis, we presented in-hospital mortality by baseline eGFR $(>90,60$ $89,30-59$, and $<30 \mathrm{~mL} / \mathrm{min} / 1.73 \mathrm{~m}^{2}$ ) and AKI status, with $95 \%$ confidence intervals (CIs) estimated by binomial exact tests.

Finally, we conducted a multivariable logistic regression analysis to examine the independent association between the five groups and in-hospital mortality, adjusting for the aforementioned covariates and taking account of clustering by hospital using robust standard errors. We repeated the multivariable analysis according to the baseline eGFR ( $>90,60-89,30-59$, and $<30 \mathrm{~mL} /$ $\min / 1.73 \mathrm{~m}^{2}$ ) and AKI status.

As post hoc analysis, we restricted the analyses to patients receiving the emergency surgery on the day of hospital admission, who were less likely to receive preoperative management for kidney conditions than those receiving the surgery on the next day or later.

All statistical analyses were conducted using STATA version 14 (STATA Corp., Texas, USA).

\section{Results}

We included 3002 eligible patients with emergency colorectal surgery (mean age $70.3 \pm 15.4$ years, male $54.5 \%$ ) (Fig. 1). Among these, we identified 99 ESRD patients, including 82 patients with evidence of maintenance dialysis (80 with hemodialysis and 2 with peritoneal dialysis) and 17 patients with recorded diagnosis of ESRD at admission. We then identified 399 patients with CKD, including 369 patients with baseline eGFR $<60 \mathrm{~mL} / \mathrm{min} / 1.73$ $\mathrm{m}^{2}$ and 30 patients with recorded diagnosis of CKD at admission. Finally, we identified 541 patients with AKI in patients without CKD and 59 in patients with CKD (Fig. 1).

Baseline characteristics are shown in Table 1. Although proportion of sex and type of surgery were not significantly different among the five groups, age distribution was significantly different: patients with CKD and/or AKI were apparently older than those in the CKD(-)AKI(-) and ESRD groups. Details of indication for surgery and proportion of colorectal cancer were also significantly different among the five groups. Notably, peritonitis or perforation was more common, while colorectal cancer was less common in patients with ESRD. Prevalence of diabetes and heart failure, as well as all the blood test results showed significant differences among the five groups. In particular, patients with CKD and ESRD showed lower hemoglobin levels, while patients with AKI showed higher C-reactive protein levels.

The in-hospital mortality was $8.6 \%$ (169/1963), 23.8\% (129/541), 15.3\% (52/340), 28.8\% (17/59), and 32.3\% (32/ 99) in the CKD(-)AKI(-), CKD(-)AKI(+), CKD(+)AKI(-), $\mathrm{CKD}(+) \mathrm{AKI}(+)$, and ESRD groups, respectively (Table 2). In subgroup analysis, among patients without AKI, inhospital mortality was around $10 \%$ in patients with baseline eGFR > 90, 60-89, and $30-59 \mathrm{~mL} / \mathrm{min} / 1.73 \mathrm{~m}^{2}$, whereas in-hospital mortality in patients with baseline eGFR $<30 \mathrm{~mL} / \mathrm{min} / 1.73 \mathrm{~m}^{2}$ and ESRD was over $30 \%$ (Fig. 2). Among patients with AKI, in-hospital mortality was over $20 \%$ regardless of baseline kidney function.

Secondary outcomes, including vasopressors, mechanical ventilation, blood transfusion, post-operative RRT, and length of hospital stay showed similar trends with inhospital mortality (Table 2). For example, the proportion of patients with any blood transfusion was $30.2 \%, 56.8 \%$, $46.8 \%, 55.9 \%$, and $68.7 \%$, whereas post-operative RRT was $4.0 \%, 11.3 \%, 10.6 \%, 28.8 \%$, and $96.0 \%$ in the CKD(-)AKI(-), CKD(-)AKI(+), CKD(+)AKI(-), CKD(+)AKI(+), and ESRD groups, respectively.

In multivariable logistic regression analysis, compared to the CKD(-)AKI(-) group, the adjusted odds ratio (95\% CI) for in-hospital mortality was 2.54 (1.90-3.40), 1.29 (0.90-1.85), 2.86 (1.54-5.32), and $2.76(1.55-4.93)$ in the $\mathrm{CKD}(-) \mathrm{AKI}(+), \quad \mathrm{CKD}(+) \mathrm{AKI}(-), \quad \mathrm{CKD}(+) \mathrm{AKI}(+), \quad$ and ESRD groups, respectively (Table 3 ). Among covariates, higher age, type of surgery, and cancer (except for colorectal cancer) were positively associated with increased risk of in-hospital death, whereas use of laparoscopy (probably because this factor suggests that patients were less severe), higher BMI, higher hemoglobin level, platelet count, and total protein level were negatively associated with in-hospital death. In subgroup analysis (Additional file 3), the shape of the association between 
Table 1 Baseline characteristics of study participants with emergency colorectal surgery

\begin{tabular}{|c|c|c|c|c|c|c|c|}
\hline & $\begin{array}{l}\text { Total } \\
n=3002\end{array}$ & $\begin{array}{l}\text { CKD(-)AKI(-) } \\
n=1963\end{array}$ & $\begin{array}{l}\text { CKD(-)AKI(+) } \\
n=541\end{array}$ & $\begin{array}{l}\text { CKD(+)AKI(-) } \\
n=340\end{array}$ & $\begin{array}{l}\mathrm{CKD}(+) \operatorname{AKI}(+) \\
n=59\end{array}$ & $\begin{array}{l}\text { ESRD } \\
n=99\end{array}$ & $P$ value \\
\hline Age (years), mean $\pm S D$ & $70.3 \pm 15.4$ & $66.9 \pm 16.1$ & $76.8 \pm 12.3$ & $77.7 \pm 10.8$ & $78.9 \pm 9.4$ & $72.5 \pm 10.8$ & $<0.001$ \\
\hline Sex (male), \% & 54.5 & 45.5 & 46.8 & 44.7 & 47.5 & 40.4 & 0.815 \\
\hline Type of surgery, \% & & & & & & & 0.927 \\
\hline $\begin{array}{l}\text { Surgery for acute } \\
\text { pan-peritonitis }\end{array}$ & 19.8 & 19.6 & 20.5 & 18.5 & 23.7 & 21.2 & \\
\hline Colectomy & 57.2 & 56.8 & 58.4 & 57.4 & 57.6 & 58.6 & \\
\hline Colostomy & 13.6 & 14.1 & 11.8 & 15.0 & 10.2 & 9.1 & \\
\hline Rectal resection & 9.4 & 9.5 & 9.2 & 9.1 & 8.5 & 11.1 & \\
\hline Use of laparoscopy, \% & 4.0 & 5.0 & 1.5 & 3.2 & 0 & 1.0 & 0.001 \\
\hline Indication for surgery, \% & & & & & & & $<0.001$ \\
\hline Peritonitis or perforation & 62.8 & 58.9 & 75.1 & 57.9 & 71.2 & 84.9 & \\
\hline Obstruction & 25.3 & 27.4 & 18.3 & 30.3 & 23.7 & 5.1 & \\
\hline Bleeding or diverticulosis & 2.3 & 2.5 & 0.9 & 3.8 & 1.7 & 1.0 & \\
\hline Others & 9.6 & 11.2 & 5.7 & 7.9 & 3.4 & 9.1 & \\
\hline $\begin{array}{l}\text { Presence of colorectal } \\
\text { cancer, } \%\end{array}$ & 38.6 & 42.5 & 33.6 & 35.0 & 23.7 & 10.1 & $<0.001$ \\
\hline $\begin{array}{l}\text { Body mass index }\left(\mathrm{kg} / \mathrm{m}^{2}\right) \\
\text { mean } \pm \mathrm{SD}\end{array}$ & $21.3 \pm 4.2$ & $21.3 \pm 4.2$ & $21.5 \pm 4.3$ & $21.1 \pm 3.8$ & $21.6 \pm 3.7$ & $20.4 \pm 4.2$ & 0.108 \\
\hline \multicolumn{8}{|l|}{ Comorbidities, \% } \\
\hline Diabetes & 14.4 & 12.2 & 14.6 & 21.8 & 20.3 & 27.3 & $<0.001$ \\
\hline Heart failure & 4.0 & 2.5 & 4.4 & 10.6 & 3.4 & 9.1 & $<0.001$ \\
\hline $\begin{array}{l}\text { Chronic pulmonary } \\
\text { disease }\end{array}$ & 3.8 & 4.0 & 3.9 & 3.8 & 1.7 & 2.0 & 0.786 \\
\hline Chronic liver disease & 2.4 & 1.9 & 2.8 & 3.5 & 6.8 & 2.0 & 0.062 \\
\hline $\begin{array}{l}\text { Cancer (except for } \\
\text { colorectal cancer) }\end{array}$ & 16.9 & 16.7 & 13.1 & 18.2 & 15.3 & 9.1 & 0.067 \\
\hline \multicolumn{8}{|l|}{$\begin{array}{l}\text { Serum creatinine tests } \\
\text { median } \\
\text {, } \\
\text { MQR] }\end{array}$} \\
\hline $\begin{array}{l}\text { Baseline creatinine } \\
(\mathrm{mg} / \mathrm{dl})\end{array}$ & $0.75[0.59-0.81]$ & $0.72[0.59-0.80]$ & $0.72[0.57-0.77]$ & 1.07 [0.89-1.41] & 1.01 [0.82-1.37] & - & $<0.001$ \\
\hline $\begin{array}{l}\text { Admission creatinine } \\
(\mathrm{mg} / \mathrm{dl})\end{array}$ & 0.80 [0.64-1.07] & 0.70 [0.59-0.83] & 1.37 [1.14-1.90] & 1.07 [0.83-1.44] & 1.90 [1.56-2.84] & - & $<0.001$ \\
\hline \multicolumn{8}{|l|}{$\begin{array}{l}\text { Blood tests at admission, } \\
\text { median [IQR] }\end{array}$} \\
\hline White blood cell count $(/ 1000 \mu \mathrm{l})$ & $8.5[5.0-12.5]$ & $8.8[5.4-12.8]$ & $8.1[4.4-12.8]$ & $7.9[5.07-10.8]$ & $9.2[5.1-12.5]$ & $5.0[2.8-9.7]$ & $<0.001$ \\
\hline Hemoglobin (g/dl) & $12.1[10.0-13.8]$ & $12.6[10.5-14.0]$ & $11.4[9.6-13.6]$ & $11.2[9.4-12.9]$ & $11.0[8.8-12.6]$ & $10.5[9.0-11.7]$ & $<0.001$ \\
\hline Platelet count $(/ 10,000 \mu \mathrm{l})$ & $21.5[16.1-28.6]$ & 22.7 [17.4-29.7] & $19.7[14.3-26.9]$ & 19.7 [14.4-26.5] & $17.0[13.5-26.2]$ & $15.0[9.8-20.6]$ & $<0.001$ \\
\hline Total protein (g/dl) & $6.2[5.1-7.0]$ & $6.3[5.3-7.0]$ & $5.9[4.6-6.8]$ & $6.1[5.1-6.9]$ & $5.9[4.9-6.8]$ & $6.0[5.2-6.7]$ & $<0.001$ \\
\hline Total bilirubin (mg/dl) & $0.7[0.5-1.0]$ & $0.7[0.5-1.0]$ & $0.8[0.5-1.1]$ & $0.7[0.5-1.0]$ & $0.7[0.5-1.2]$ & $0.4[0.3-0.6]$ & $<0.001$ \\
\hline $\begin{array}{l}\text { C-reactive protein } \\
(\mathrm{mg} / \mathrm{dl})\end{array}$ & $3.9[0.5-14.2]$ & $2.7[0.3-11.9]$ & $11.6[2.3-22.0]$ & $2.8[0.5-12.7]$ & $13.6[3.4-21.8]$ & $4.8[1.0-16.0]$ & $<0.001$ \\
\hline
\end{tabular}

$A K I$ acute kidney injury, CKD chronic kidney disease, eGFR estimated glomerular filtration rate, ESRD end-stage renal disease, IQR interquartile range, $S D$ standard deviation

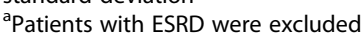

baseline eGFR ( $>90,60-89,30-59$, and $<30 \mathrm{~mL} / \mathrm{min} /$ $1.73 \mathrm{~m}^{2}$ ) and AKI status, and in-hospital mortality was similar to that of the crude analysis: the adjusted odds ratio for in-hospital mortality increased in patients with baseline eGFR $<30 \mathrm{~mL} / \mathrm{min} / 1.73 \mathrm{~m}^{2}$ and ESRD among patients without AKI, while the adjusted odds ratio was constantly high regardless of the baseline eGFR among patients with AKI. 
Table 2 In-hospital outcomes of study participants with emergency colorectal surgery

\begin{tabular}{|c|c|c|c|c|c|c|c|}
\hline & $\begin{array}{l}\text { Total } \\
n=3002\end{array}$ & $\begin{array}{l}\text { CKD(-)AKI(-) } \\
n=1963\end{array}$ & $\begin{array}{l}\text { CKD(-)AKI(+) } \\
n=541\end{array}$ & $\begin{array}{l}\text { CKD(+)AKI(-) } \\
n=340\end{array}$ & $\begin{array}{l}\text { CKD(+)AKI (+) } \\
n=59\end{array}$ & $\begin{array}{l}\text { ESRD } \\
n=99\end{array}$ & $P$ value \\
\hline \multicolumn{8}{|l|}{ Primary outcome } \\
\hline In-hospital mortality, \% & 13.3 & 8.6 & 23.8 & 15.3 & 28.8 & 32.3 & $<0.001$ \\
\hline \multicolumn{8}{|l|}{ Secondary outcomes } \\
\hline $\begin{array}{l}\text { Use of mechanical ventilation on } \\
\text { the next day of surgery or later, } \%\end{array}$ & 26.9 & 21.1 & 43.8 & 24.7 & 44.1 & 46.5 & $<0.001$ \\
\hline $\begin{array}{l}\text { Use of mechanical ventilation on } \\
\text { the next day of surgery or later, } \%\end{array}$ & 6.5 & 4.0 & 10.7 & 8.2 & 15.3 & 21.2 & $<0.001$ \\
\hline $\begin{array}{l}\text { Blood transfusion during } \\
\text { hospitalization, \% }\end{array}$ & 38.6 & 30.2 & 56.8 & 46.8 & 55.9 & 68.7 & $<0.001$ \\
\hline Red cell concentrate, \% & 35.1 & 27.3 & 51.2 & 43.2 & 52.5 & 63.6 & $<0.001$ \\
\hline Platelet concentrate, \% & 4.7 & 3.0 & 8.3 & 4.1 & 10.2 & 16.2 & $<0.001$ \\
\hline Fresh-frozen plasma, \% & 24.3 & 18.0 & 41.0 & 25.0 & 39.0 & 45.5 & $<0.001$ \\
\hline Post-operative RRT, $\%$ & 9.6 & 4.0 & 11.3 & 10.6 & 28.8 & 96.0 & $<0.001$ \\
\hline Continuous RRT, \% & 7.3 & 3.8 & 10.4 & 8.5 & 22.0 & 46.5 & $<0.001$ \\
\hline Intermittent RRT, \% & 4.2 & 0.4 & 2.0 & 2.9 & 11.9 & 90.9 & $<0.001$ \\
\hline $\begin{array}{l}\text { Length of hospital stay in } \\
\text { hospital survivors (days), } \\
\text { median [IQR] }\end{array}$ & $23[14-40]$ & 21 [13-35] & $33[20-55]$ & 27 [16-42] & 37 [18-58] & 34 [24-69] & $<0.001$ \\
\hline
\end{tabular}

AKI acute kidney injury, CKD chronic kidney disease, ESRD end-stage renal disease, IQR interquartile range, RRT renal replacement therapy

In post hoc analysis restricting to 2162 patients $(72 \%$ of the study participants) receiving the emergency surgery on the day of hospital admission, the results were similar to those of the main analysis, with more prominent differences between the groups: the crude in-hospital mortality was $7.7 \%(108 / 1,396), 23.5 \%(101 / 430), 15.6 \%$ $(35 / 224), 37.5 \%(15 / 40)$, and $29.2 \%(21 / 72)$ in the CKD(-
)AKI(-), CKD(-)AKI(+), CKD(+)AKI(-), CKD(+)AKI(+), and ESRD groups, respectively, and the adjusted odds ratio $(95 \% \mathrm{CI})$ for in-hospital mortality was 2.95 (2.054.25), $1.54(0.88-2.70), 5.69(2.52-12.84)$, and 2.87 $(1.40-5.89)$ in the $\mathrm{CKD}(-) \mathrm{AKI}(+), \quad \mathrm{CKD}(+) \mathrm{AKI}(-)$, $\mathrm{CKD}(+) \mathrm{AKI}(+)$, and ESRD groups, respectively, compared to the $\mathrm{CKD}(-) \mathrm{AKI}(-)$ group.

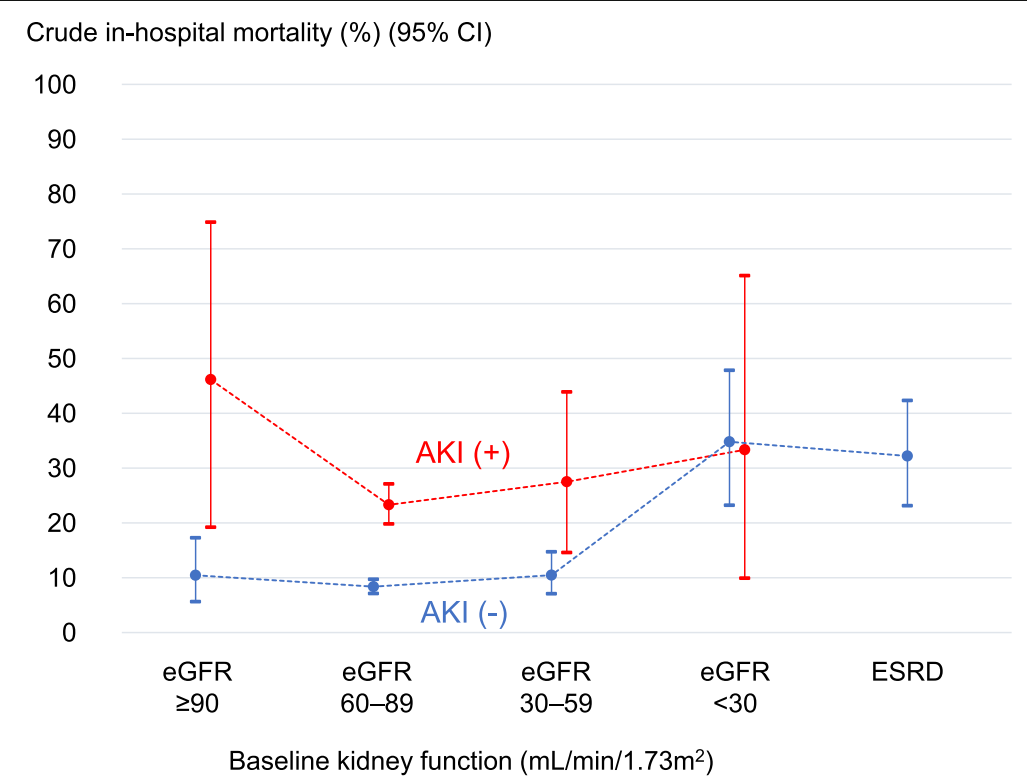

Fig. 2 Crude in-hospital mortality by level of baseline kidney function and acute kidney injury status. Cl, confidence interval; AKl, acute kidney injury; eGFR, estimated glomerular filtration rate; ESRD, end-stage renal disease 
Table 3 Multivariable logistic regression analysis for in-hospital mortality

\begin{tabular}{|c|c|c|}
\hline & Adjusted odds ratio $(95 \% \mathrm{Cl})$ & $P$ value \\
\hline \multicolumn{3}{|l|}{ Exposure groups } \\
\hline (i) $\mathrm{CKD}(-) \mathrm{AKI}(-)$ & 1 (reference) & \\
\hline (ii) $\mathrm{CKD}(-) \mathrm{AKI}(+)$ & $2.54(1.90-3.40)$ & $<0.001$ \\
\hline (iii) $\mathrm{CKD}(+) \mathrm{AKI}(-)$ & $1.29(0.90-1.85)$ & 0.166 \\
\hline (iv) $\mathrm{CKD}(+) \mathrm{AKI}(+)$ & $2.86(1.54-5.32)$ & 0.001 \\
\hline (v) ESRD & $2.76(1.55-4.93)$ & 0.001 \\
\hline \multicolumn{3}{|l|}{ Covariates } \\
\hline Age (per 1 year) & $1.03(1.02-1.05)$ & $<0.001$ \\
\hline Sex (men vs. women) & $1.39(1.00-1.93)$ & 0.051 \\
\hline \multicolumn{3}{|l|}{ Type of surgery } \\
\hline Surgery for acute pan-peritonitis & 1 (reference) & \\
\hline Colectomy & $1.67(1.14-2.45)$ & 0.009 \\
\hline Colostomy & $2.40(1.38-4.17)$ & 0.002 \\
\hline Rectal resection & $1.68(0.98-2.87)$ & 0.057 \\
\hline Use of laparoscopy (yes vs. no) & $0.22(0.07-0.71)$ & 0.012 \\
\hline \multicolumn{3}{|l|}{ Indication for surgery } \\
\hline Peritonitis or perforation & $2.69(0.55-13.13)$ & 0.220 \\
\hline Obstruction & $4.06(0.93-17.80)$ & 0.063 \\
\hline Bleeding or diverticulosis & 1 (reference) & \\
\hline Others & $2.40(0.51-11.23)$ & 0.266 \\
\hline Presence of colorectal cancer (yes vs. no) & $0.92(0.62-1.35)$ & 0.671 \\
\hline Body mass index (per 1 kg/m²) & $0.94(0.91-0.98)$ & 0.001 \\
\hline \multicolumn{3}{|l|}{ Comorbidities (yes vs. no) } \\
\hline Diabetes & $1.24(0.96-1.61)$ & 0.095 \\
\hline Heart failure & $1.66(0.85-3.24)$ & 0.135 \\
\hline Chronic pulmonary disease & $1.14(0.59-2.21)$ & 0.699 \\
\hline Chronic liver disease & $1.31(0.71-2.40)$ & 0.383 \\
\hline Cancer (except for colorectal cancer) & $1.81(1.32-2.46)$ & $<0.001$ \\
\hline \multicolumn{3}{|l|}{ Blood test results at admission } \\
\hline 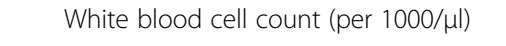 & $1.01(0.98-1.04)$ & 0.478 \\
\hline Hemoglobin (per $1 \mathrm{~g} / \mathrm{dl}$ ) & $0.90(0.85-0.95)$ & $<0.001$ \\
\hline Platelet count (per 10,000/ul) & $0.98(0.96-0.99)$ & 0.020 \\
\hline Total protein (per $1 \mathrm{~g} / \mathrm{dl}$ ) & $0.88(0.80-0.96)$ & 0.005 \\
\hline Total bilirubin (per $1 \mathrm{mg} / \mathrm{dl}$ ) & $0.95(0.74-1.23)$ & 0.700 \\
\hline C-reactive protein (per $1 \mathrm{mg} / \mathrm{dl}$ ) & $1.00(0.99-1.01)$ & 0.588 \\
\hline
\end{tabular}

AKI acute kidney injury, CKD chronic kidney disease, $C I$ confidence interval, eGFR estimated glomerular filtration rate, ESRD end-stage renal disease

\section{Discussion}

Using a large database including over 3000 patients with emergency colorectal surgery in 38 community hospitals, we examined the association of pre-operative status of CKD and/or AKI with in-hospital outcomes. In crude analysis, the largest in-hospital mortality was observed in patients with ESRD (32.3\%), followed by those with both CKD and AKI (28.8\%), those with AKI only (23.8\%), those with CKD only (15.3\%), and those with neither
CKD nor AKI (8.6\%). In subgroup analysis, the inhospital mortality increased from $<30 \mathrm{~mL} / \mathrm{min} / 1.73 \mathrm{~m}^{2}$ among patients without AKI, while the in-hospital mortality of patients with AKI was constantly high regardless of baseline kidney function. In adjusted analysis, CKD only was not significantly associated with increased mortality, but AKI only, AKI superimposed on CKD, and ESRD were independently associated with increased mortality. 
Previous studies showed that there was an independent and graded association between CKD and poor patient outcomes, including cardiovascular events, hospitalization, and death $[17,18]$. This was also found to be true in patients hospitalized for elective surgery: patients with renal dysfunction showed high post-operative mortality and morbidity [5, 19-21]. The worse prognosis in patients with decreased kidney function can be explained through a variety of mechanisms, including poor wound healing, post-operative infection due to decreased immunity, and coagulopathic disorders due to altered blood viscosity.

However, in emergency surgery, patients may also have pre-operative AKI, with or without baseline CKD. Potential reasons for AKI in emergency colorectal surgery include sepsis from peritonitis or bacterial translocation and renal ischemia from dehydration or bleeding [22]. Emergency operation can remove these underlying causes of AKI, and therefore, some people may expect that patients with pre-operative AKI would show better prognoses than those with pre-operative CKD. However, in our real-world data, patients in the $\mathrm{CKD}(-) \mathrm{AKI}(+)$ group showed rather worse mortality and morbidity than those in the $\mathrm{CKD}(+) \mathrm{AKI}(-)$ group and similar mortality with the ESRD group (Table 2). We speculate that patients with pre-operative AKI may be more likely to suffer from dysfunction of homeostasis, which are important for post-operative recovery [23].

Despite several studies showing an association between the post-operative incidence of AKI and worse mortality and morbidity in patients with elective surgery [24, 25], our study is the first to suggest the need for more attention for pre-operative AKI in the case of emergency surgery. In a previous study, some predictors (e.g., preoperative sepsis or septic shock, number of comorbidities) of surgical mortality in patients with colorectal perforation were identified; however, the impact of preoperative kidney function was not examined [22]. In addition to the current study indicating that preoperative AKI is a good predictor for outcomes of emergency colorectal surgery, future studies are warranted to examine how clinicians, including surgeons, anesthesiologists, and nephrologists, could adopt a different approach to improve surgical outcomes in patients with and without pre-operative AKI. There may be some strategies to improve pre-operative kidney function in short pre-operative period (e.g., to postpone the surgery until urine output is established), while the majority (72\%) of the study participants in our current study received the surgery immediately on the day of hospital admission.

We hereby acknowledge several limitations of the study. First, although our study findings were obtained from 38 community hospitals in Japan, its external validity may be limited to other Japanese hospitals (e.g., university hospital) and other countries. Notably, patients included in this Japanese study were slim, with mean BMI of $21.3 \pm 4.2 \mathrm{~kg} / \mathrm{m}^{2}$. The association between kidney function and outcomes of emergency colorectal surgery may be different in obese patients because obesity is associated with CKD [26], AKI [27], and surgical outcomes [28, 29]. Second, like most observational studies on kidney diseases, not all patients had their baseline kidney function measured in the community. We used the best available approach to classify pre-operative CKD and AKI, in line with the recent KDIGO CKD and AKI guidelines $[2,6]$. However, misclassification of CKD and AKI status is still possible, and some patients in the CKD(-)AKI(-) group might have had CKD or AKI. If this was the case, the in-hospital mortality of patients in the CKD(-)AKI(-) group may have been overestimated, indicating that the true association between pre-operative CKD and/or AKI and in-hospital mortality may be larger than the adjusted odds ratios obtained in the current study. Third, there may be some unmeasured confounding factors in the association between kidney function and in-hospital outcomes. For example, we could not access operative notes in the current study; therefore, details of operation remained unknown. There may be some anesthesiologic and other measures that may increase the chance of better outcomes of emergent patients with AKI or CKD. It is also possible that complications due to surgical techniques or surgical decision-making caused post-operative AKI or directly influenced mortality and morbidity, but we were unable to take these into account in our analysis. In addition, it was difficult to define some surgical outcomes that we were originally interested in, such as wound infection and drain trouble, uniformly, in the 38 hospitals. Finally, although this study is one of the largest studies in this field, statistical power may still be limited in some analyses. A lack of independent association between CKD only and in-hospital mortality (adjusted odds ratio 1.29, 95\% CI 0.90-1.85) may be possibly due to insufficient study power. In our subgroup analysis by baseline kidney function (Fig. 2 and Additional file 3), some groups showed wide CIs due to the small sample sizes. Further subgroup analysis, especially based on the AKI stage, was difficult.

As for clinical implications of the current study focusing on risk stratification, the study findings can be used to inform patients (and their family members) of their prognosis more accurately than before as part of informed consent. As for research implications, further research is warranted to investigate whether patient outcomes can be modified by directly intervening in the kidney function (e.g., postponing the surgery, with preoperative fluid management, until urine output is established) or taking different treatment approach (e.g., 
aiming at different peri-operative arterial blood pressure) according to the pre-operative CKD and AKI status.

\section{Conclusions}

This large study showed that the in-hospital outcomes of emergency colorectal surgery were significantly different according to the pre-operative status of CKD, AKI, and ESRD. CKD only was not significantly associated with increased mortality, but AKI only, AKI superimposed on CKD, and ESRD were independently associated with increased mortality. Thus, differentiation of preoperative CKD and AKI is warranted for risk stratification in patients undergoing emergency colorectal surgery.

\section{Supplementary information}

Supplementary information accompanies this paper at https://doi.org/10. 1186/s13017-020-00303-6.

\section{Additional file 1. List of 38 hospitals in the Tokushukai Medical} Database.

Additional file 2. List of International Classification Disease of 10th revision codes to classify indication for surgery.

Additional file 3. Multivariable logistic regression analysis by level of baseline kidney function and acute kidney injury status. AKI = acute kidney injury, eGFR = estimated glomerular filtration rate, ESRD = endstage renal disease.

\section{Abbreviations}

AKI: Acute kidney injury; BMI: Body mass index; Cl: Confidence interval; CKD: Chronic kidney disease; DPC: Diagnosis Procedure Combination; eGFR: Estimated glomerular filtration rate; ESRD: End-stage renal disease; ICD10: International Classification Disease 10th revision; IQR: Interquartile range: KDIGO: Kidney Disease Improving Global Outcomes; RRT: Renal replacement therapy; SD: Standard deviation

\section{Acknowledgements}

The authors thank the 38 hospitals (Additional file 1) for their contribution to the Tokushukai Medical Database. We would like to thank Editage (www. editage.jp) for English language editing.

\section{Authors' contributions}

KM and MI had full access to all of the data in the study and takes responsibility for the integrity of the data and the accuracy of the data analysis, under the supervision of TO, HM, and SK. KM, MI, TO, HM, NK, TM, TN, YM, NI, KI, RS, SH, HK, JK, HO, and SK contributed to the concept and design, as well as interpretation of the results. KM and $\mathrm{Ml}$ drafted the manuscript, and TO, HM, NK, TM, TN, YM, NI, KI, RS, SH, HK, JK, HO, and SK substantially improved the manuscript. All authors read and approved the final manuscript.

\section{Funding}

This study is self-funded in the Tokushukai Group, without outside funding.

\section{Availability of data and materials}

The data that support the findings of this study are available from the Tokushukai Group, Japan, but restrictions apply to the availability of these data, which were used under license for the current study, and so are not publicly available.

\section{Ethics approval and consent to participate}

The study was approved by the Tokushukai Group Joint Ethics Committee (reference number TGE00947-024) and conducted in adherence with the tenets of the Declaration of Helsinki. Informed consent from individual patients was waived because all data were anonymized for research purposes.

\section{Consent for publication}

Not applicable.

\section{Competing interests}

The authors declare that they have no competing interests.

\section{Author details}

${ }^{1}$ Kidney Disease and Transplant Center, Shonan Kamakura General Hospital, Kanagawa, Japan. ${ }^{2}$ Columbia Center for Translational Immunology, Columbia University Medical Center, New York, NY, USA. ${ }^{3}$ Department of Urology, Tokyo Women's Medical University, Tokyo, Japan. ${ }^{4}$ Department of Health Services Research, University of Tsukuba, Ibaraki, Japan. ${ }^{5}$ Department of Non-Communicable Disease Epidemiology, London School of Hygiene and Tropical Medicine, London, UK. ${ }^{6}$ Department of Surgery, Shonan Kamakura General Hospital, Kanagawa, Japan. ${ }^{7}$ Narita Tomisato Tokushukai Hospital, Chiba, Japan.

Received: 23 January 2020 Accepted: 12 March 2020

Published online: 26 March 2020

\section{References}

1. National Kidney Foundation. K/DOQI clinical practice guidelines for chronic kidney disease: evaluation, classification, and stratification. Am J Kidney Dis. 2002;39(2 Suppl 1):S1-266

2. KDIGO. 2012 clinical practice guideline for the evaluation and management of chronic kidney disease. Kidney Int Suppl. 2013:3:1-150.

3. Mathew A, Devereaux PJ, O'Hare A, Tonelli M, Thiessen-Philbrook H, Nevis IF, et al. Chronic kidney disease and postoperative mortality: a systematic review and meta-analysis. Kidney Int. 2008;73:1069-81.

4. Mooney JF, Ranasinghe I, Chow CK, Perkovic V, Barzi F, Zoungas S, et al. Preoperative estimates of glomerular filtration rate as predictors of outcome after surgery: a systematic review and meta-analysis. Anesthesiology. 2013; 18:809-24.

5. Cloyd JM, Ma Y, Morton JM, Kurella Tamura M, Poultsides GA, Visser BC Does chronic kidney disease affect outcomes after major abdominal surgery? Results from the National Surgical Quality Improvement Program. J Gastrointest Surg. 2014;8:605-12.

6. The Kidney Disease: Improving Global Outcomes (KDIGO) Acute Kidney Injury Work Group. KDIGO clinical practice guideline for acute kidney injury. Kidney Int Suppl. 2012;2:1-138

7. Gameiro J, Fonseca JA, Neves M, Jorge S, Lopes JA. Acute kidney injury in major abdominal surgery: incidence, risk factors, pathogenesis and outcomes. Ann Intensive Care. 2018:8:22.

8. Ortega-Loubon C, Fernandez-Molina M, Carrascal-Hinojal Y, Fulquet-Carreras E. Cardiac surgery-associated acute kidney injury. Ann Card Anaesth. 2016; 19(4):687-98.

9. Hobson C, Ozrazgat-Baslanti T, Kuxhausen A, Thottakkara P, Efron PA, Moore FA, et al. Cost and mortality associated with postoperative acute kidney injury. Ann Surg. 2015;261:1207-14

10. Rewa O, Bagshaw SM. Acute kidney injury-epidemiology, outcomes and economics. Nat Rev Nephrol. 2014;10:193-207.

11. Iwagami M, Moriya H, Doi K, Yasunaga H, Isshiki R, Sato I, et al. Seasonality of acute kidney injury incidence and mortality among hospitalized patients. Nephrol Dial Transplant. 2018:33:1354-62.

12. Wang K, Li P, Chen L, Kato K, Kobayashi M, Yamauchi K. Impact of the Japanese diagnosis procedure combination-based payment system in Japan. J Med Syst. 2010;34:95-100.

13. World Health Organization. International Classification of Diseases (ICD)-10, 2003 Version. 2nd ed; 2003. http://apps.who.int/classifications/apps/icd/icd1 0online2003/fr-icd.htm.

14. Yamana $H$, Moriwaki $M$, Horiguchi $H$, Kodan $M$, Fushimi $K$, Yasunaga $H$. Validity of diagnoses, procedures, and laboratory data in Japanese administrative data. J Epidemiol. 2017:27:476-82

15. Matsuo S, Imai E, Horio M, Yasuda Y, Tomita K, Nitta K, et al. Revised equations for estimated GFR from serum creatinine in Japan. Am J Kidney Dis. 2009;53:982-92. 
16. Zeng X, MCMahon GM, Brunelli SM, Bates DW, Waikar SS. Incidence, outcomes, and comparisons across definitions of AKI in hospitalized individuals. Clin J Am Soc Nephrol. 2014;9:12-20.

17. Go AS, Chertow GM, Fan D, McCulloch CE, Hsu CY. Chronic kidney disease and the risks of death, cardiovascular events, and hospitalization. N Engl J Med. 2004;351:1296-305.

18. Khan SS, Kazmi WH, Abichandani R, Tighiouart H, Pereira BJ, Kausz AT. Health care utilization among patients with chronic kidney disease. Kidney Int. 2002;62:229-36.

19. Drolet S, Maclean AR, Myers RP, Shaheen AA, Dixon E, Donald BW. Morbidity and mortality following colorectal surgery in patients with endstage renal failure: a population-based study. Dis Colon Rectum. 2010;53: 1508-16.

20. Wind P, Douard R, Rouzier R, Berger A, Bony C, Cugnenc PH. Abdominal surgery in chronic hemodialysis patients. Am Surg. 1999;65:347-51.

21. Sirany AM, Chow CJ, Kunitake H, Madoff RD, Rothenberger DA, Kwaan MR. Colorectal surgery outcomes in chronic dialysis patients: an American College of Surgeons National Surgical Quality Improvement Program Study. Dis Colon Rectum. 2016;59:662-9.

22. Hsu CW, Wang JH, Kung YH, Chang MC. What is the predictor of surgical mortality in adult colorectal perforation? The clinical characteristics and results of a multivariate logistic regression analysis. Surg Today. 2017;47: 683-9.

23. Lobo DN, Bostock KA, Neal KR, Perkins AC, Rowlands BJ, Allison SP. Effect of salt and water balance on recovery of gastrointestinal function after elective colonic resection: a randomised controlled trial. Lancet. 2002;359:1812-8.

24. O'Connor ME, Kirwan CJ, Pearse RM, Prowle JR. Incidence and associations of acute kidney injury after major abdominal surgery. Intensive Care Med. 2016;42:521-30

25. Bihorac A, Yavas S, Subbiah S, Hobson CE, Schold JD, Gabrielli A. Long-term risk of mortality and acute kidney injury during hospitalization after major surgery. Ann Surg. 2009;249:851-8.

26. Kovesdy CP, Furth SL, Zoccali C. Obesity and kidney disease: hidden consequences of the epidemic. Kidney Int. 2017;91:260-2.

27. Danziger J, Chen KP, Lee J, Feng M, Mark RG, Celi LA, et al. Obesity, acute kidney injury, and mortality in critical illness. Critical Care Med. 2016;44:328-34.

28. Yasunaga $\mathrm{H}$, Horiguchi $\mathrm{H}$, Matsuda S, Fushimi K, Hashimoto H, Ayanian JZ. Body mass index and outcomes following gastrointestinal cancer surgery in Japan. Br J Surg. 2013:100:1335-43.

29. Mullen JT, Moorman DW, Davenport DL. The obesity paradox: body mass index and outcomes in patients undergoing nonbariatric general surgery. Annals of surgery. 2009;250:166-72.

\section{Publisher's Note}

Springer Nature remains neutral with regard to jurisdictional claims in published maps and institutional affiliations.

Ready to submit your research? Choose BMC and benefit from:

- fast, convenient online submission

- thorough peer review by experienced researchers in your field

- rapid publication on acceptance

- support for research data, including large and complex data types

- gold Open Access which fosters wider collaboration and increased citations

- maximum visibility for your research: over $100 \mathrm{M}$ website views per year

At $\mathrm{BMC}$, research is always in progress.

Learn more biomedcentral.com/submissions 